\title{
A formação profissional de terapeutas ocupacionais e o curso de graduaçáo da Universidade de Brasília, Faculdade de Ceilândia ${ }^{1}$
}

\author{
Paula Giovana Furlan ${ }^{a}$, Ioneide de Oliveira Campos ${ }^{a}$, Kátia Vanessa Pinto de Meneses ${ }^{a}$, \\ Hellayne Meneses Ribeiro ${ }^{a}$, Lorrayne Marjory Menezes Rodrigues ${ }^{a}$ \\ ${ }^{a}$ Curso de Terapia Ocupacional, \\ Faculdade de Ceilândia, Universidade de Brasília, DF, Brasil
}

\begin{abstract}
Resumo: A formação em saúde vem sendo debatida no campo educacional, orientando mudanças curriculares dos cursos de graduação de acordo com as políticas públicas atuais, principalmente o Sistema Único de Saúde e as novas diretrizes curriculares. Almeja-se a capacitação profissional com base na busca ativa do conhecimento e na garantia da integralidade e humanização da atenção à saúde. Nessa perspectiva, este artigo apresenta uma revisão bibliográfica sobre as produções científicas relacionadas à formação em saúde, especificamente a formação do terapeuta ocupacional, e verifica de que forma o projeto político pedagógico do Curso de Graduação em Terapia Ocupacional da Universidade de Brasília - Faculdade de Ceilândia (UnB-FCE) contempla e prioriza uma formação orientada pelas tendências atuais. Foram encontrados 14 artigos científicos que apontaram para a reformulação dos currículos de cursos de graduação, favorecendo a interdisciplinaridade e atividades práticas em equipamentos sociais. A prática docente e postura discente interferem no processo educacional, havendo o desafio do desenvolvimento de habilidades comunicativas, afetivas e relacionais em contraponto ao modelo pedagógico bancário. O Curso de Terapia Ocupacional da UnB-FCE é recente e visa à formação de acordo com o novo modelo proposto. Organiza-se em relação aos campos de atuação profissional, à funcionalidade humana e prioriza o desenvolvimento local comunitário através das atividades de ensino, pesquisa e extensão com articulação dos serviços de saúde do Distrito Federal.
\end{abstract}

Palavras-chave: Terapia Ocupacional, Ensino, Ocupações em Saúde/Educação.

\section{The vocational training of occupational therapists and the Undergraduate Course at the University of Brasília, Ceilândia College}

\begin{abstract}
Health training has been discussed in the educational field, guiding curriculum changes for undergraduate courses according to the current public policies, mainly the National Health System and the new Curriculum Guidelines. Professional formation based on the active pursuit of knowledge, ensuring integrality and humanization of health care, is objectified. In this perspective, this article presents a literature review on the scientific production related to health training, specifically the training of occupational therapists, and examines how the political pedagogical project of the occupational therapy undergraduate course of the University of Brasília - Ceilândia College (UnB-FCE) contemplates and prioritizes vocational training guided by current trends. We found 14 scientific articles addressing the reformulation of the curricula of undergraduate courses, favoring interdisciplinarity and practical activities in social infrastructure. The teaching practice and the student body posture interfere in the educational process, with the challenge of developing communicative, affective and relational skills in contrast with the current teaching model. The undergraduate program in occupational therapy of UnB-FCE is recent, and it aims at vocational training under the new proposed model. It is organized in relation to the fields of professional practice and human functionality, and it prioritizes the local community development through teaching, research, and extension projects associated with the health services of the Federal District.
\end{abstract}

Keywords: Occupational Therapy, Teaching, Health/Education Occupations.

Autor para correspondência: Paula Giovana Furlan, Unidade de Ensino e Docência, Faculdade de Ceilândia, Universidade de Brasília, Centro Metropolitano, conjunto A, Lt. 1, Ceilândia Sul, CEP 72220-900, Brasília, DF, Brasil, e-mail: paulafurlan@unb.br 


\section{Introdução}

A formação em saúde e a flexibilização dos currículos nos cursos de graduação vêm sendo questionadas há muitos anos, antes mesmo do Sistema Único de Saúde (SUS) ser implantado no Brasil (TRENCHE; BARZAGHI; PUPO, 2008; CECCIM; CARVALHO, 2011). Convergem, durante todo o século XX, a contestação da insuficiência do modelo biomédico para formação em saúde e o reconhecimento da necessidade de aspectos sociais pautarem o desenvolvimento de competências e habilidades profissionais para a introdução na pauta dos currículos de cursos de graduação dos temas reforma sanitária brasileira, integralidade e cuidado. A partir, principalmente, das décadas de 1980 e 1990 , projetos governamentais estimularam reformas educacionais desafiando a mudança de conteúdos via a integraçáo ensino-serviço, além da saúde preventivista e curativa, para um enfoque comunitário participativo (CECCIM; CARVALHO, 2011). Naquele período, o Ministério da Educação juntamente com o Ministério da Saúde estabeleceram diretrizes e estimularam a revisão de Projetos Político-Pedagógicos (PPPs) para que contemplassem a importância da articulação do ensino com a prática no modelo de atenção à saúde definido pelo SUS e suas reais necessidades (BRASIL, 2002). O foco do cuidado centrado na patologia passou a ser considerado também pelas capacidades e funcionalidades dos pacientes/usuários, de acordo com a Classificaçáo Internacional de Funcionalidade (CIF) (ORGANIZAÇÃO, 2001). O SUS, com seus princípios doutrinários e organizacionais (BRASIL, 1990), apresentou uma nova forma de cuidar da saúde, valorizando as potencialidades em uma atenção contextualizada pela realidade de vida dos indivíduos e do seu espaço territorial, com enfoque em açôes integradas de redes de serviços (BRASIL, 2006).

Em 1996 foi promulgada a Lei das Diretrizes e Bases da Educação, que propôs a reformulação dos conteúdos curriculares, permitindo maior flexibilidade em sua construção e indicando as áreas de conhecimento a serem abordadas, sem estabelecer disciplinas e cargas horárias definidas, favorecendo maior compromisso entre instituiçóes formadoras em saúde e o SUS. Uma das recomendações foi de que a capacitação profissional ocorresse com base na busca do conhecimento e na garantia da integralidade e humanização da atenção à saúde.

A reforma sanitária e os debates em torno da educação superior reforçavam que as políticas públicas de saúde deveriam reordenar o processo de formação profissional na área de saúde. Essa responsabilidade, nas últimas décadas, foi compreendida como o compromisso de contribuir na orientação da formação de recursos humanos em coerência com as diretrizes constitucionais da saúde (CAMPOS et al., 2001). A necessidade e a importância da mudança curricular são observadas no cotidiano dos hospitais, clínicas, centros de saúde e outros equipamentos sociais através das práticas e atitudes que não consideram o contexto de vida do paciente e suas potencialidades (processo chamado por MERHY; FRANCO, 2003 de trabalho vivo) e não contemplam políticas e práticas de humanização em saúde.

Diante dessa nova orientação, as instituiçóes de ensino superior foram provocadas a reverem e a repensarem seus PPPs a fim de disparar constante avaliação das práticas e dos pressupostos do processo educacional, com a valorização da equidade, eficiência e qualidade nas ações de saúde. Esse processo apresenta o desafio de romper com a tradiçáo do ensino vertical e da transmissão passiva do conhecimento. As estratégias de problematização do cotidiano, o incentivo à busca do conhecimento e compartilhamento dos saberes de professores e alunos têm sido valorizados por apresentarem resultados nesse sentido (CAVALCANTI, 2005; JÓFILI, 2002; CYRINO; TORALLES-PEREIRA, 2004; BERBEL, 1998).

Processo semelhante às demais áreas de formação de profissionais da saúde, a graduação de terapeutas ocupacionais enfrenta o debate da herança do modelo biomédico, voltado para tratar as doenças, os processos incapacitantes e as partes do corpo, com intervenções voltadas para a remissão de sintomas e a cura, com o incentivo da formação por especialidades médicas. A partir das reformas propostas, não se trata mais de formar um profissional apto a relacionar-se com a doença/deficiência, mas da necessidade de adoção de uma estratégia prática de ensino voltada para a reconstruçấo da complexidade do contexto social, o trabalho em equipe e as práticas cuidadoras, considerando que na intervenção profissional sempre há implicações culturais, sociais, éticas e políticas.

Nessa perspectiva, os cursos de terapia ocupacional vêm discutindo e reformulando seu currículo, propondo novos enfoques e abordagens teóricometodológicas, de forma a atender as demandas atuais e delinear um novo perfil profissional capaz de promover sua inserção no mercado de trabalho (BORINI; PALM, 1997; DRUMMOND; RODRIGUES, 2004; RODRIGUES et al., 2011; FURLAN et al., 2012).

$\mathrm{Na}$ proposição de discutirmos a formação do terapeuta ocupacional, as fragmentaçôes e possibilidades no campo educacional e da saúde, este artigo objetivou uma revisão bibliográfica sobre 
as produçôes científicas relacionadas à formação em saúde, especificamente a do terapeuta ocupacional, e verificar de que forma, especificamente o projeto político pedagógico do Curso de Terapia Ocupacional da Universidade de Brasília - Faculdade de Ceilândia (UnB-FCE) contempla e prioriza uma formação orientada pelas tendências atuais.

\section{Metodologia}

Este artigo foi realizado a partir do referencial da pesquisa qualitativa (MINAYO, 2006; DENZIN; LINCOLN, 1994), bibliográfica e documental. Trata-se de texto inédito, que aborda parte da análise dos dados da pesquisa Avaliaçáo participativa do Curso de Graduação em Terapia Ocupacional - Faculdade de Ceilândia/UnB: Metodologias ativas e o processo de ensino-aprendizagem para a formação profissional, com financiamento do Decanato de Ensino de Graduação/ Universidade de Brasília e aprovação do Comitê de Ética em Pesquisa FS/UnB 160/11.

Para a revisão bibliográfica, foram utilizadas as bases de dados Sielo, BVS/LILACS, Cadernos de Terapia Ocupacional da UFSCar e Revista de Terapia Ocupacional da USP, a partir dos anos 1990 até 2011, com base nos descritores: docentes e terapia ocupacional, habilidades e terapia ocupacional, formação em saúde e terapia ocupacional, formação profissional e terapia ocupacional, educação e terapia ocupacional, ensino em saúde, práticas docentes, práticas profissionais. Foram critérios de inclusão: artigos científicos completos em português que tratassem do tema da formação profissional de alunos de graduação na área da saúde e da terapia ocupacional.

Foram encontrados 32 artigos (15 no Scielo, sete nos Cadernos de Terapia Ocupacional da UFSCar e dez no LILACS), sendo selecionados, de acordo com os critérios de inclusão, 14 artigos (sete no Scielo, três nos Cadernos de Terapia Ocupacional da UFSCar e quatro no LILACS), detalhados na Tabela 1.

Tivemos ainda como fonte de dados, o PPP do Curso de Graduaçáo em Terapia Ocupacional UnB-FCE. Foi realizada análise qualitativa temática do material com base nas categorias: formaçáo profissional em saúde e formação profissional em terapia ocupacional.

\section{Resultados e considerações}

Serão apresentados pontos do redirecionamento da formação em saúde, da formação em terapia ocupacional e, posteriormente, verificadas as perspectivas do PPP do Curso de Terapia Ocupacional da UnB-FCE.

Da revisão bibliográfica, foram selecionados 14 artigos, explicitados na Tabela 1.

Assume relevância no contexto atual brasileiro o desafio de uma prática que ultrapasse o domínio do conhecimento técnico-científico e se estenda pelas relações, pelas ações comunicativas, pelos afetos e pela estruturação das práticas de cuidado à saúde (CECCIM; FEUERWERKER, 2004b), tendo o SUS e o Sistema Único de Assistência Social (SUAS) como parâmetros de organização das açôes e saberes.

Porém, para que essa prática seja efetiva, são necessários profissionais capacitados para lidar com essa realidade. Segundo Ceccim e Feuerwerker (2004a), uma das áreas que possui mais defasagem dentro do SUS é a da formação dos profissionais; por causa desse problema é proposto que através da integralidade da saúde seja elaborado um currículo que assegure que esse princípio básico seja implementado durante a formação dos estudantes da área da saúde. Os autores referem-se também ao projeto do governo que visa contribuir para a melhoria da formação dos profissionais de saúde tendo como referência a ideia de educaçáo permanente em saúde, que vem orientando as políticas do ministério nessa área, e a articulação entre os diferentes saberes e práticas produzidos nas próprias instituições, nos serviços de saúde e no contato com a população.

A formação na saúde continua centrada em tecnologias altamente especializadas, alheia à organização local e às demandas sociais. Uma formação em saúde para o SUS deveria permitir que o cotidiano das relaçóes da organização da gestão setorial e estruturação do cuidado se incorporasse ao aprender e ao ensinar (CECCIM; FEUERWERKER, 2004b).

A imagem do quadrilátero da formação para a área da saúde - ensino/gestáo setorial/práticas de atenção/controle social - propóe construir e organizar uma educação responsável por processos interativos e de ação na realidade para operar mudanças (desejo de futuro), mobilizar caminhos (negociar e pactuar processos), convocar protagonismos (pedagogia in acto) e detectar a paisagem interativa e móvel de indivíduos, coletivos e instituições como cenários de conhecimentos e invençôes (cartografia permanente) (CECCIM; FEUERWERKER, 2004b, p. 59).

Para Bagnato e Monteiro (2006), essa orientação racional e técnica presente nos cursos de graduaçáo na área da saúde baseia-se nos pressupostos tayloristas, 
Tabela 1. Artigos selecionados na revisão bibliográfica

\begin{tabular}{|c|c|c|}
\hline Ano & Base de dados & Referência completa \\
\hline 1999 & Scielo & $\begin{array}{l}\text { ROZENDO, C. A. et al. Uma análise das práticas docentes de professores } \\
\text { universitários da área de saúde. Revista Latino-Americana de Enfermagem, } \\
\text { Ribeirão Preto, v. 7, n. 2, p. 15-23, abr. } 1999 .\end{array}$ \\
\hline 2000 & $\begin{array}{l}\text { Cadernos de Terapia } \\
\text { Ocupacional da } \\
\quad \text { UFSCar }\end{array}$ & $\begin{array}{l}\text { PFEIFER, L. I. Trabalhando a formação de Terapeutas ocupacional reflexivos. } \\
\text { Cadernos de Terapia Ocupacional da UFSCar, São Carlos, v. 8, n. 2, p. 103- } \\
\text { 111, } 2000 .\end{array}$ \\
\hline 2004 & Scielo & $\begin{array}{l}\text { CECCIM, R. B.; FEUERWERKER, L. C. M. Mudança na graduação das } \\
\text { profissões de saúde sob o eixo da integralidade. Cadernos de Saúde Pública, } \\
\text { Rio de Janeiro, v. } 20 \text {, n. 5, p. 1400-1410, set./out. 2004a. }\end{array}$ \\
\hline 2004 & LILACS & $\begin{array}{l}\text { DRUMMOND, A. F.; RODRIGUES, A. M. V. N. Os desafios da implantação } \\
\text { de uma proposta de flexibilização curricular nos cursos de terapia ocupacional. } \\
\text { Revista de Terapia Ocupacional da USP, São Paulo, v. 15, n. 3, p. 106-11, set./ } \\
\text { dez. } 2004 \text {. }\end{array}$ \\
\hline 2004 & Scielo & $\begin{array}{l}\text { CECCIM, R. B.; FEUERWERKER, L. C. M. O quadrilátero da formação para } \\
\text { a área da saúde: ensino, gestão, atenção e controle social. Physis: Revista de } \\
\text { Saúde Coletiva, Rio de Janeiro, v. 14, n. 1, p. 41-65, 2004b. }\end{array}$ \\
\hline 2004 & $\begin{array}{l}\text { Cadernos de Terapia } \\
\text { Ocupacional da } \\
\quad \text { UFSCar }\end{array}$ & $\begin{array}{l}\text { CRUZ, D. M. C.; CAMPOS, I. O. A opinião de Estudantes de Terapia } \\
\text { Ocupacional sobre o processo de sua Formação Profissional. Cadernos de } \\
\text { Terapia Ocupacional da UFSCar, São Carlos, v. 12, n. 2, p. 105-114, } 2004 .\end{array}$ \\
\hline 2005 & Scielo & $\begin{array}{l}\text { LIMA, V. V. Competência: distintas abordagens e implicações na formação de } \\
\text { profissionais da saúde. Interface: Comunicação, Saúde, Educação, Botucatu, } \\
\text { v. } 9 \text {, n. } 17 \text {, p.369-79, mar./ago. } 2005 \text {. }\end{array}$ \\
\hline 2006 & Scielo & $\begin{array}{l}\text { BAGNATO, M. H. S.; MONTEIRO, M. I. Perspectivas interdisciplinar e } \\
\text { rizomática na formação dos profissionais da saúde. Revista Trabalho, Educação } \\
\text { e Saúde, Rio de Janeiro, v. 4, n. 2, p. } 247-258,2006 .\end{array}$ \\
\hline 2008 & LILACS & $\begin{array}{l}\text { LOPES, R. E. et al. XI Encontro Nacional de Docentes de Terapia Ocupacional: } \\
\text { refletindo sobre os processos de formação acadêmica e profissional. Revista de } \\
\text { Terapia Ocupacional da USP, São Paulo, v. 19, n. 3, p. 159-166, set./dez. } 2008 \text {. }\end{array}$ \\
\hline 2008 & LILACS & $\begin{array}{l}\text { BRITO, C. M. D. Formação do terapeuta ocupacional no século XXI. Revista } \\
\text { Baiana de Saúde Pública, Salvador, v. 32, p. 34-41, out. 2008. Suplemento } 1 .\end{array}$ \\
\hline 2009 & Scielo & $\begin{array}{l}\text { SANTANA, C. S. et al. Reflexões sobre a prática de tutoria com estudantes de } \\
\text { terapia ocupacional. Revista Trabalho, Educação e Saúde, Rio de Janeiro, v. } 7 \text {, } \\
\text { n. 1, p. 167-182, 2009. }\end{array}$ \\
\hline 2010 & LILACS & $\begin{array}{l}\text { LOPES, R. E. et al. Educação profissional, pesquisa e aprendizagem no } \\
\text { território: notas sobre a experiência de formação de Terapeutas Ocupacionais. } \\
\text { O Mundo da Saúde, São Paulo, v. 34, n. 2, p. 140-147, } 2010 .\end{array}$ \\
\hline 2010 & Scielo & $\begin{array}{l}\text { GOMES, M. P. C. et al. O uso de metodologias ativas no ensino de graduação } \\
\text { nas ciências sociais e da saúde: avaliação dos estudantes. Ciência \& Educação, } \\
\text { Bauru, v. } 16, \text { n. 1, p. } 181-198,2010 \text {. }\end{array}$ \\
\hline 2011 & $\begin{array}{l}\text { Cadernos de Terapia } \\
\text { Ocupacional da } \\
\text { UFSCar }\end{array}$ & $\begin{array}{l}\text { RODRIGUES, C. P. G. et al. Um olhar para a comunidade: experiência } \\
\text { necessária para a formação do Terapeuta Ocupacional. Cadernos de Terapia } \\
\text { Ocupacional da UFSCar, São Carlos, v. 19, n. 3, p. 343-350, } 2011 .\end{array}$ \\
\hline
\end{tabular}

em que a valorização do trabalho fragmentado e o aumento da capacidade técnica tendem a se articular às demandas imediatas do mercado mas não necessariamente às demandas do contexto social. Os autores discutem as perspectivas interdisciplinar e rizomática na formação profissional como deslocamento desse olhar técnico rumo a diferentes olhares das realidades político-socioculturais de atuação profissional.
Com relação às práticas docentes, Rozendo et al. (1999) realizaram um estudo para essa caracterização da formação em saúde (planejamento, execução, métodos e recursos didáticos e avaliação do ensino-aprendizagem) na Universidade de São Paulo. Constataram que a prática predominante ainda é aquela em que o educando é subordinado à autoridade do educador (modelo de educação bancária criticado por Paulo Freire), sendo o saber imposto ou comunicado verticalmente, havendo 
pouco questionamento por parte dos alunos ou abertura de diálogo por parte dos professores, com uso excessivo de aulas expositivas. Nessa pesquisa, apontaram que muitos professores, mesmo com doutorado, não dão relevância ao desenvolvimento de habilidades para práticas pedagógicas e encaram que o aluno universitário (sendo um jovem adulto) seria a priori capaz de aprender sozinho, apoiando pouco o seu processo de aprendizado.

Sobre esta questão, Ceccim e Feuerwerker (2004a) mencionam que no ensino superior, na perspectiva tradicional, ainda se desconhecem as estratégias didático-pedagógicas ou modos de ensinar problematizadores, construtivistas ou com protagonismo ativo dos estudantes, ignorando-se o acúmulo de conhecimento na Educação relativo à construção das aprendizagens, da produção e circulação de saberes na contemporaneidade.

Para Rozendo et al. (1999), esse cenário vem se modificando com as atuais avaliaçóes do ensino superior em que, em várias universidades, os alunos, ao responderem questionários sobre o desempenho de seus professores, apontam a competência técnica suficiente, porém a dificuldade em práticas didáticas mais participativas. Dessa maneira, as estratégias didático-pedagógicas no campo da saúde devem ser permeadas pelo diálogo como possibilidade para a troca de saberes com orientação horizontal, que envolve um processo educativo participativo, autônomo e de corresponsabilizaçáo entre educadores e alunos.

Assim, pensar a formação do terapeuta ocupacional para as práticas de atenção e gestão no SUS para além do domínio técnico-científico da profissão e se estender aos aspectos subjetivos, éticos, políticos e estéticos presentes nas práticas de saúde delineia-se como um desafio. Desse modo, nos últimos anos, os questionamentos sobre as práticas da terapia ocupacional, aliados a diversos movimentos na área da saúde e no contexto social, a formulação de políticas sociais e de saúde para as diversas áreas de atuação trouxeram um redimensionamento nas intervençôes nesse núcleo profissional.

No sentido de priorizar um ensino voltado às demandas sociais e a incorporação de reflexão contextual da realidade no processo ensinoaprendizagem são realizados, desde a década de 1980 , encontros nacionais de docentes de terapia ocupacional, a fim de promover debates sobre as questôes específicas da formação profissional (LOPES et al., 2008). A discussão sobre a complexidade da formação de recursos humanos integrada às atuais demandas sociais coloca a necessidade de buscarem-se novos cenários e propostas de ensino no Curso de Terapia Ocupacional. Para isso são necessárias práticas pedagógicas que incorporem a reflexão contextual da realidade, mediadas por um processo de ensino-aprendizagem interativo. As políticas atuais que preconizam a formação profissional sob a perspectiva da integralidade nas açôes de saúde, bem como na educação e na assistência social, têm permitido maior aprofundamento do debate e do desenvolvimento de estratégias que visam essa formação superior integrada (LOPES et al., 2008).

A World Federation of Occupational Therapy, desde sua fundação, em 1952, reconhece a necessidade de estabelecer orientaçóes para a formação e capacitação de terapeutas ocupacionais, sendo uma de suas preocupaçóes o desenvolvimento de atividades práticas específicas ao longo da graduação, desde a observação até a prática assistida (WORLD..., 2002). A revisão dos parâmetros mínimos curriculares para a graduaçáo do terapeuta ocupacional foi lastreada pela visão da relação do ensino com a demanda social e comunitária (LOPES et al., 2010), enfocando a mudança:

da orientação universal ao culturalmente sensível; do enfoque biomédico à perspectiva ocupacional; do diagnóstico em saúde à saúde e ao bem-estar; do individual ao enfoque em grupos e populaçóes; da ênfase no tratamento ao maior enfoque na prevenção e promoção da saúde; do conteúdo acadêmico às competências dos graduados; da prescrição ao processo e desenvolvimento. Definiu, ainda, os aspectos essenciais do conhecimento, habilidades e atitudes que os graduados devem demonstrar: relação pessoa-ocupação-meio ambiente e suas articulações com a saúde, relações terapêuticas e profissionais, processo de terapia ocupacional, raciocínio e comportamento profissional e contexto da prática profissional (LOPES et al., 2008, p. 162).

Nessa direção é oportuno mencionar algumas experiências de ensino em determinados Cursos de Terapia Ocupacional no Brasil, que demonstram certa ruptura com a linearidade na formação profissional, considerando vivências e experiências na relação entre educadores e estudantes. Rodrigues et al. (2011) relataram uma experiência de estágio curricular supervisionado de Terapia Ocupacional em Saúde Coletiva em que foi possível aproximar estudantes de um dado contexto da realidade no território e de suas demandas. Com base nos seguintes aspectos metodológicos: vivência, acompanhamento de projetos e socialização em rodas de conversa, esse processo vivencial proporcionou aos alunos aquisição 
da capacidade de identificar a própria dinâmica da comunidade, o reconhecimento de redes de suporte social e o desenvolvimento de habilidades para atuar no território. A adoção desse tipo de perspectiva no contexto da formação do terapeuta ocupacional remete ao que Bagnato e Monteiro (2006) caracterizaram como uma formaçáo para além da dimensão técnica, incluindo as dimensóes política e cultural.

Outra experiência, descrita por Santana et al. (2009), sobre um processo de tutoria desenvolvido no Curso de Terapia Ocupacional da Universidade de São Paulo, mostra um outro processo dentro desse cenário da formação profissional, que assume o pensar e o fazer educaçấo, instaurando outras lógicas de aproximação entre professor e aluno e, sobretudo, na compreensão da realidade da vida universitária em sua multidimensionalidade.

Assim, essas experiências compóem a nova flexibilizaçáo do currículo, discutida por Drummond e Rodrigues (2004), e buscam achar alternativas à construção de um novo currículo de terapia ocupacional, pautado nos princípios propostos pela política pública, que inclua a integralidade como garantia do fornecimento de um conjunto articulado e contínuo de açóes e serviços preventivos, curativos e coletivos, exigidos em cada caso para todos os níveis de complexidade de assistência. E, além disso, propicie um processo de aprendizagem que permita aos estudantes a aquisiçáo de conhecimentos tendo como premissa a observação da realidade e a reflexão crítica sobre as açôes dos sujeitos (GOMES et al., 2010).

Para Pfeifer (2000), a formação profissional se desenvolveria a partir de três fatores: a legislação (o conjunto de leis e diretrizes gerais), os conteúdos da formação (conhecimentos sistematizados referentes ao objeto de estudo) e a dinâmica do processo (funcionamento administrativo, atuação do professor e atuação do aluno). Pfeifer (2000) defende que uma formação centrada no raciocínio clínico, na reflexão crítica e na problematização prepararia os terapeutas ocupacionais para a autonomia na prática profissional e para processos de autoaprendizagem (formação continuada). O aluno teria que, diante do contexto atual, ter habilidade para resolver problemas e desenvolver o conhecimento prático, envolvendo conhecimento, reflexão e ação.

Cruz e Campos (2004) discutem que formar um terapeuta ocupacional exige uma não dissociação de questôes pessoais, do autoconhecimento, de consideraçáo da história pessoal no processo de aprendizado. O docente teria papel fundamental na articulação dos saberes, assim como das vivências do curso de graduaçáo, com as experiências prévias do aluno.

Acrescenta-se a isso uma questáo fundamental apresentada por Morin (apud BRITO, 2008), que diz que em um mundo complexo é preciso ensinar os métodos que permitem estabelecer as relaçóes mútuas e as influências recíprocas entre as partes e o todo. Não basta ter acesso às informaçóes; é preciso aprender a organizá-las e articulá-las. Saber isolado não é funcional, por isso a ideia de ensinar uma disciplina, de dominar um conhecimento muito específico não gera a competência necessária no mundo complexo em que vivemos. Essa definição de Morin dialoga com a própria terapia ocupacional enquanto profissão, no sentido de que os indivíduos devem ampliar as percepçóes de si mesmos, das relaçôes de mundo, dos potenciais possíveis de construção e reconstrução do cotidiano. É nessa potência que o terapeuta ocupacional atua, e transpondo para o processo de ensino-aprendizagem o docente deve estabelecer relaçóes para produzir o agir na contemporaneidade, portanto não é um transmissor de informaçóes e técnicas, mas deve oferecer aos alunos a oportunidade de experienciarem situações que favoreçam o desenvolvimento de suas competências interpessoais, autoconhecimento, comunicação e relacionamento interpessoal, questóes essas cruciais na mudança curricular.

Há ainda os autores que trabalham com o termo competência no campo da mudança curricular da formação profissional. $\mathrm{O}$ conceito ganhou força na medida da mudança no padrão de exigência do profissional, não reduzida mais ao conhecimento técnico mas agregada às disposiçóes e qualidades pessoais para dar conta das transformaçóes do trabalho no contemporâneo. Para tanto, os saberes tácitos, a comunicaçáo e o trabalho intelectualizado, a participação, a autonomia e o compromisso passaram a ser valorizados na estrutura do trabalho e nas suas atividades (LALUNA, 2007).

Segundo Lima (2005), a competência não é observável diretamente, mas inferida por desempenho. Esse, por sua vez, torna-se o indicador que favorece

[...] a análise integrada dos atributos (cognitivos, atitudinais e hábeis) em ação, considerando o contexto e as relaçóes ali estabelecidas, quando pautados na noção dialógica de competência (LALUNA, 2007, p. 110).

Se a única avaliação utilizada é a prova escrita tradicional, ganha ênfase o atributo cognitivo em detrimento dos demais, não possibilitando uma avaliação global. Na perspectiva da avaliação tradicional, a preocupação do professor dirige-se ao 
erro e à sua correção, ao passo que na perspectiva democrática, a avaliação serviria à investigação sobre o processo do aluno, disparando indagaçóes em busca do conhecimento e da reorientação do processo de aprendizagem (LALUNA, 2007).

\section{O Curso de Terapia} Ocupacional da Universidade de Brasília - Faculdade de Ceilândia

A Universidade de Brasília, criada com o objetivo de estabelecer um novo padrão de universidade brasileira na formaçấo de cientistas e técnicos atuantes e inovadores para a promoção do desenvolvimento do país e do Distrito Federal, reforçou o cumprimento de sua missão institucional e educacional quando o seu Conselho Universitário aprovou, em sua $333^{\mathrm{a}}$ reuniáo, em 19 de outubro de 2007, o documento "A UnB rumo aos 50 anos: Autonomia, Qualidade e Compromisso Social" e a "Carta de Intençôes" para seu ingresso no Programa de Apoio a Planos de Reestruturação e Expansão das Universidades Federais (Reuni), Ministério da Educação (MEC). Com a proposta de descentralizaçáo do ensino criaram-se três campi universitários, um deles é a Faculdade de Ceilândia (FCE), que deu início, em 2008, a cinco cursos de graduação na área da saúde, inclusive o de Terapia Ocupacional, propondo um novo modelo de currículo baseado nas diretrizes do SUS. Parte da concepção de educação em que o estudante universitário é um sujeito pleno de possibilidades e que não se limita a uma função meramente instrumental. Uma educaçáo que náo se coloca a serviço da reprodução ou da mera transmissão de informaçôes, valores e crenças que imobilizam sujeitos e coletividades.

O Curso de Terapia Ocupacional da UnB-FCE contempla os modelos de atençáo a saúde (atenção básica, média complexidade e alta complexidade, bem como promoção da saúde) e possui um currículo inovador e generalista que busca a integração entre o ensino e a prática, atividades de extensão e pesquisa. Valoriza a formação focada na funcionalidade humana em cenários de prática profissional que atendam as atuais políticas públicas de saúde, de assistência social, de trabalho e de educação, promovendo a inclusão social, contribuindo com a evolução e melhor contextualização do terapeuta ocupacional enquanto profissional de saúde.

O projeto pedagógico aqui descrito utiliza as Diretrizes Curriculares Nacionais (DCN) (BRASIL, 2002), mantendo dessa forma a coerência e legalidade da proposta. Propóe a integraçáo entre as áreas biológicas, humanas e sociais, ciências exatas, saúde e áreas profissionalizantes específicas, incluindo uma perspectiva de transformação social e econômica da populaçâo regional no caso da região administrativa de Ceilândia, no Distrito Federal.

No âmbito geral, a estrutura curricular está configurada de modo a assegurar aos discentes o contato e a experiência em conteúdos, abordagens e situaçôes práticas de articulação no ensino e nos serviços de maneira integrada.

Tal estrutura é direcionada por três eixos estruturantes distribuídos em estruturas interdependentes. $\mathrm{O}$ primeiro eixo estruturante relaciona-se aos conhecimentos previstos nas DCN e definidas por núcleos, a saber:

- Núcleo Modo de Vida, que apresenta um predomínio de conteúdos e abordagens voltadas à aproximação dos estudantes com o processo de trabalho enquanto produção e reprodução da sociedade em nível local, regional e geral; as relaçóes sociais que lhe são características e o campo de saberes e práticas em saúde que lhe são inerentes;

- Núcleo de Sistemas Biológicos, que se desenvolve privilegiando conteúdos e abordagens voltadas à compreensão dos sistemas biológicos que podem ser afetados durante o processo saúde-doença;

- Núcleo Instrumentalização em Terapia Ocupacional, que enfatiza aqueles aspectos, conteúdos e abordagens voltados à qualificação da ação dos estudantes nas questôes diretamente implicadas na aplicação técnica da atividade humana enquanto recurso terapêutico;

- Núcleo Cenários das Práticas em Terapia Ocupacional, que enfatiza conteúdos, abordagens e vivências voltadas ao exercício da reflexão e proposição de práticas em terapia ocupacional (eixo vertical na Figura 1).

Nos dois primeiros núcleos de formação estão distribuídos os conteúdos essenciais relativos às Ciências Biológicas e da Saúde, bem como às Ciências Sociais e Humanas. Nos dois últimos núcleos encontram-se os módulos em que serão discutidos conteúdos por meio de blocos temáticos que estão relacionados às áreas de conhecimento relativas às Ciências da Terapia Ocupacional previstas nas DCN.

Embora cada núcleo concentre, por razôes didáticas, um conjunto de conteúdos e abordagens próprias, ao longo do curso o corpo discente terá a oportunidade de entrar em contato com elementos 
dos quatro núcleos de formação, interagindo com os outros eixos estruturantes, ainda que com graus de profundidade distintos durante o processo de formação.

Os outros dois eixos estruturantes definem: habilidades e competências previstas nas DCN, que estão delineadas e contextualizadas no processo saúdedoença conforme os níveis de atenção preconizados pelo SUS. Dessa forma, o estudante de terapia ocupacional será capacitado a desenvolver habilidades e competências para avaliaçáo, utilizaçáo de recursos terapêuticos e intervenção em terapia ocupacional nos cenários de prática profissional da Atenção Básica, Atenção de Média e de Alta Complexidade (eixos horizontal e diagonal na Figura 1).

No âmbito específico, o projeto pedagógico está estruturado para responder às necessidades de formação, em nível de graduaçáo, de profissional em saúde capacitado a atuar em todos os níveis de sua atenção, com visão ampla e global da ocupação humana, em todas as suas formas de expressão individual e coletiva, por meio da atividade humana aplicada enquanto recurso terapêutico, o que é próprio de seus atos privativos.

Para tanto, orienta-se por metodologias ativas e emancipadoras, que têm como eixo principal a construção de competências e habilidades que valorizem o significado da experiência do discente e a sua individualidade. Seguem alguns dos enfoques contextualizados nessa proposta:

- Manutenção da saúde, entendida em um enfoque ampliado, incorporando a visão subjetiva dos sujeitos, a sua percepção sobre saúde e qualidade de vida;

- Processo saúde-doença, oriundo não só dos fenômenos biológicos, mas também resultante do modo como os seres humanos estabelecem relaçôes com o meio, incluindo-se nessas as que eles estabelecem entre si, enquanto indivíduos ou grupos, um processo que compreende os fatores de vida, de adoecimento e de morte dos seres humanos, permeando o ciclo vital, envolvendo as dimensóes espirituais, relacionais e éticas, em um contexto socioeconômico e cultural;

- Atenção à saúde, com base nos princípios do SUS, que supóem a integralidade das ações, o trabalho em equipe multiprofissional e transdisciplinar, centradas em atitudes éticas e políticas, em sintonia com a corresponsabilidade, intersetorialidade, reconhecendo os limites do conhecimento e das tecnologias, possibilitando a construção de relações contínuas como forma de responder às necessidades sociais de qualidade de vida e saúde;

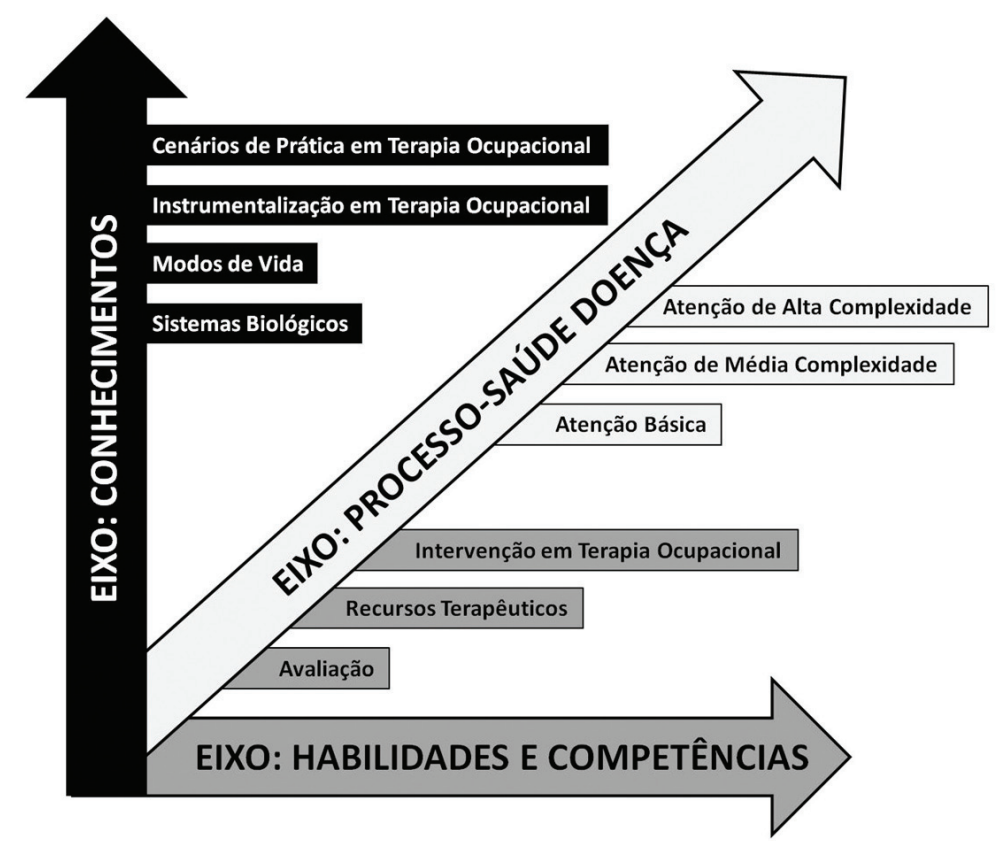

Figura 1. Esquema ilustrando o desenho curricular do Curso de Terapia Ocupacional apresentando os eixos estruturantes (conhecimentos, processo saúde-doença e habilidades e competências) e seus respectivos núcleos de formação, que serão desenvolvidos simultânea e progressivamente durante a formação do terapeuta ocupacional, definindo o perfil pretendido para o egresso. 
- Funcionalidade humana, entendida pelas perspectivas do corpo, do indivíduo e da sociedade; a expressão funcionalidade humana é então definida pelas estruturas e funções corporais, pelas atividades humanas e pela participaçáo em nível individual e coletivo, contrapondo-se ao termo deficiência, que se caracteriza por limitação às atividades humanas e restrição à participação individual e coletiva, em um modelo de funcionalidade, incapacidade e saúde;

- Processo permanente de formação: Considerando que a graduação, com a sua terminalidade, é uma etapa do processo da formação que continua ao longo da vida profissional do indivíduo, esse projeto possibilita a continuidade do processo de formação, por meio da pós-graduação e da educação permanente, que valorizam a gestáo do conhecimento como uma atividade que compóe o cotidiano das atividades da rede de serviços (FARIAS; BUCHALLA, 2005; GUPTA, 2006).

Finalmente, no âmbito complementar estão previstas atividades de pesquisa e de extensão que oferecerão possibilidades adicionais de ensino e contato profissional durante toda a formação, as quais estão dispostas náo necessariamente de maneira linear e progressiva. Da mesma forma, as atividades teóricas e práticas da formação específica em terapia ocupacional são desenvolvidas gradualmente desde o início do curso.

Anualmente, desde 2011 vêm sendo realizados os Fóruns de Discussão Curricular do Curso de Graduação em Terapia Ocupacional, que buscam o encontro dos docentes, alunos e direção da FCE para avaliação, revisão e atualização do currículo, das ementas e planos de ensino, bem como das atividades desenvolvidas em sala de aula e nos serviços da rede pública do Distrito Federal. Reorganizamos os conteúdos didáticos a partir da experiência docente e discente dos anos anteriores do curso, baseando-nos nas habilidades e nas competências esperadas de um terapeuta ocupacional e nos objetivos de cada disciplina no PPP.

Tendo em vista as questóes apresentadas, os desafios encontrados nessa perspectiva de trabalho nos convidam a repensar os caminhos da formação em terapia ocupacional na Faculdade de Ceilândia de maneira crítica, dinâmica e em sua complexidade, considerando as condiçóes estruturais bem como as questôes que perpassam o próprio processo de formaçáo, porém é nesse cenário que se tem assumido o compromisso de rever a organização curricular, de forma a priorizar uma formação pautada na integralidade e na valorizaçáo de sujeitos e processos.

A partir da revisão bibliográfica realizada verificou-se coerência entre a proposta do PPP do Curso de Terapia Ocupacional da UnB e as tendências atuais na formaçáo de profissionais de saúde, tendo em vista que o PPP propóe a flexibilização curricular, articulação entre ensino e serviço, práticas em diferentes níveis de atenção à saúde dentro do modelo definido pelo SUS, a problematizaçáo do cotidiano da população e a interdisciplinaridade. A proposta de articulação entre ensino e serviços de saúde, em que são realizadas as práticas pedagógicas, promove a divulgaçáo da profissão entre a população e entre outros profissionais de saúde e potencializa as chances de inserção do profissional no mercado de trabalho. Nesse sentido, o PPP do Curso de Terapia Ocupacional da UnB propóe a formação do terapeuta ocupacional de acordo com as políticas públicas de saúde e com a funcionalidade do sujeito, contribuindo para a transformação da realidade social e econômica do Distrito Federal.

\section{Referências}

BAGNATO, M. H. S.; MONTEIRO, M. I. Perspectivas interdisciplinar e rizomática na formação dos profissionais da saúde. Revista Trabalho, Educação e Saúde, Rio de Janeiro, v. 4, n. 2, p. 247-258, 2006.

BERBEL, N. A. N. A problematização e a aprendizagem baseada em problemas. Interface: Comunicação, Saúde, Educação, Botucatu, v. 2, p. 139-54, 1998. http://dx.doi. org/10.1590/S1414-32831998000100008

BORINI, M. A. L. O.; PALM, R. C. M. R. Reestruturação curricular do Curso de Terapia Ocupacional. Revista de Ciências Médicas-PUCCAMP, Campinas, v. 6, n. 2-3, p. 99-104, maio/dez. 1997.

BRASIL. Ministério da Saúde. $A B C$ do SUS. Brasília: Ministério da Saúde, 1990.

BRASIL. Ministério da Saúde. Entendendo o SUS. Cartilha. Brasília: Ministério da Saúde, 2006.

BRASIL. Ministério da Educação. Resolução CNE/ CES no 6, de 19 de fevereiro de 2002. Institui Diretrizes Curriculares Nacionais do Curso de Graduação em Terapia Ocupacional. Diário Oficial da República Federativa do Brasil, Brasília, 4 mar. 2002. Seção 1, p. 12. Disponível em: <http://portal.mec.gov.br>. Acesso em: 18 ago. 2010. BRITO, C. M. D. Formação do terapeuta ocupacional no século XXI. Revista Baiana de Saúde Pública, Salvador, v. 32, p. 34-41, out. 2008. Suplemento 1.

CAMPOS, F. E. et al. Caminhos para aproximar a formação de profissionais de saúde das necessidades da atenção básica. Revista Brasileira de Educação Médica, Rio de Janeiro, v. 25, n. 2, maio/ago. 2001. http://dx.doi. org/10.1590/S0100-55022009000400011 
CAVALCANTI, L. S. Cotidiano, mediação pedagógica e formação de conceitos: uma contribuição de Vygotsky ao ensino de geografia. Cadernos Cedes, Campinas, v. 25, n. 66, p. 185-207, maio/ago. 2005. http://dx.doi. org/10.1590/S0101-32622005000200004

CECCIM, R. B.; CARVALHO, Y. M. Ensino da saúde como projeto da integralidade: a educaçáo dos profissionais de saúde no SUS. In: PINHEIRO, R.; CECCIM, R. B.; MATTOS, R. A. Ensinar na saúde: a integralidade e o SUS nos cursos de graduação na área da saúde. Rio de Janeiro: CEPESC; IMS; UERJ; ABRASCO, 2011. p. 69-92.

CECCIM, R. B.; FEUERWERKER, L. C. M. Mudança na graduação das profissóes de saúde sob o eixo da integralidade. Cadernos de Saúde Pública, Rio de Janeiro, v. 20, n. 5, p. 1400-1410, set./out. 2004a. http://dx.doi. org/10.1590/S0102-311X2004000500036

CECCIM, R. B.; FEUERWERKER, L. C. M. O quadrilátero da formação para a área da saúde: ensino, gestão, atenção e controle social. Physis: Revista de Saúde Coletiva, Rio de Janeiro, v. 14, n. 1, p. 41-65, 2004 b. http://dx.doi.org/10.1590/S0103-73312004000100004

CRUZ, D. M.; CAMPOS, I. O. A opinião de Estudantes de Terapia Ocupacional sobre o processo de sua Formação Profissional. Cadernos de Terapia Ocupacional da UFSCar, São Carlos, v. 12, n. 2, p. 105-114, 2004.

CYRINO, E. G.; TORALLES-PEREIRA, M. L. Trabalhando com estratégias de ensino-aprendizado por descoberta na área da saúde: a problematização e a aprendizagem baseada em problemas. Cadernos de Saúde Pública, Rio de Janeiro, v. 20, n. 3, p.780788, maio/jun. 2004. http://dx.doi.org/10.1590/ S0102-311X2004000300015

DENZIN, N. K.; LINCOLN, Y. S. Handbook of qualitative research. Thousand Oaks: Sage, 1994

DRUMMOND, A. F.; RODRIGUES, A. M. V. N. Os desafios da implantaçáo de uma proposta de flexibilizaçáo curricular nos cursos de terapia ocupacional. Revista de Terapia Ocupacional da USP, São Paulo, v. 15, n. 3, p. 106-11, set./dez. 2004. http://dx.doi.org/10.11606/ issn.2238-6149.v15i3p106-111

FARIAS, N.; BUCHALLA, C. M. The international classification of functioning, disability and health: concepts, uses and perspectives. Revista Brasileira de Epidemiologia, São Paulo, v. 8, n. 2, p.187-193, 2005. http://dx.doi.org/10.1590/S1415-790X2005000200011

FURLAN, P. G. et al. Avaliaçâo participativa do curso de Graduação em Terapia Ocupacional FCE/UnB: metodologias ativas e o processo de ensino-aprendizagem para a formação profissional. Brasília: Universidade de Brasília, Faculdade de Ceilândia, 2012. Relatório parcial de pesquisa.

GOMES, M. P. C. et al. O uso de metodologias ativas no ensino de graduação nas ciências sociais e da saúde: avaliação dos estudantes. Ciência \& Educação, Bauru, v. 16, n. 1, p. 181-198, 2010. http://dx.doi.org/10.1590/ S1516-73132010000100011

GUPTA, J. A model for interdisciplinary service-learning experience for social change. Journal of Physical Therapy Education, Alexandria, v. 20, n. 3, p. 55-60, 2006.

JÓFILI, Z. Piaget, Vygotsky, Freire e a construção do conhecimento na escola. Educação: Teoria e Práticas, Rio Claro, v. 2, n. 2, p. 191-208, 2002.
LALUNA, M. C. M. C. Os sentidos da avaliação na formação de enfermeiros orientada por competência. 2007. 226 f. Tese (Doutorado em Enfermagem)-Escola de Enfermagem, Universidade de São Paulo, Ribeirão Preto, 2007.

LIMA, V. V. Competência: distintas abordagens e implicaçóes na formação de profissionais da saúde. Interface: Comunicação, Saúde, Educação, Botucatu, v. 9, n. 17, p.369-79, mar./ago. 2005. http://dx.doi. org/10.1590/S1414-32832005000200012

LOPES, R. E. et al. Educação profissional, pesquisa e aprendizagem no território: notas sobre a experiência de formação de Terapeutas Ocupacionais. O Mundo da Saúde, São Paulo, v. 34, n. 2, p. 140-147, 2010.

LOPES, R. E. et al. XI Encontro Nacional de Docentes de Terapia Ocupacional: refletindo sobre os processos de formação acadêmica e profissional. Revista de Terapia Ocupacional da USP, São Paulo, v. 19, n. 3, p. 159-166, set./dez. 2008. http://dx.doi.org/10.11606/issn.2238-6149. v19i3p159-166

MERHY, E. E.; FRANCO, T. B. Por uma composição técnica do trabalho centrada nas tecnologias leves e no campo relacional. Saúde em Debate, Rio de Janeiro, v. 27, n. 65, p. 1-13, set./dez. 2003.

MINAYO, M. C. S. O desafio do conhecimento: Pesquisa qualitativa em saúde. 9. ed. rev. e aprim. São Paulo: Hucitec, 2006.

ORGANIZAÇÃO MUNDIAL DA SAÚDE - OMS. Classificação Internacional de Funcionalidade. Lisboa: OMS, 2001.

PFEIFER, L. I. Trabalhando a formação de Terapeutas ocupacional reflexivos. Cadernos de Terapia Ocupacional da UFSCar, São Carlos, v. 8, n. 2, p. 103-111, 2000.

RODRIGUES, C. P. G. et al. Um olhar para a comunidade: experiência necessária para a formação do Terapeuta Ocupacional. Cadernos de Terapia Ocupacional da UFSCar, São Carlos, v. 19, n. 3, p. 343-350, 2011. http://dx.doi. org/10.4322/cto.2011.007

ROZENDO, C. A. et al. Uma análise das práticas docentes de professores universitários da área de saúde. Revista Latino-Americana de Enfermagem, Ribeirão Preto, v. 7, n. 2, p. 15-23, abr. 1999. http://dx.doi.org/10.1590/ S0104-11691999000200003

SANTANA, C. S. et al. Reflexões sobre a prática de tutoria com estudantes de terapia ocupacional. Revista Trabalho, Educação e Saúde, Rio de Janeiro, v. 7, n. 1, p. 167-182, 2009. http://dx.doi.org/10.1590/ S1981-77462009000100009

TRENCHE, M. C. B.; BARZAGHI, L.; PUPO, A. C. Mudança curricular: construção de um novo projeto pedagógico de formação na área da Fonoaudiologia. Interface: Comunicação, Saúde, Educação, Botucatu, v. 12, n. 27, p. 697-711, out./dez. 2008. http://dx.doi. org/10.1590/S1414-32832008000400002

WORLD FEDERATION OF OCCUPATIONAL THERAPY - WFOT. Revised minimum standards for the education of occupational therapists - second version. Forrestfield: WFOT, 2002. Disponível em: <www.wfot. org.au>. Acesso em: 10 julho 2012. 


\section{Contribuição dos Autores}

Paula Giovana Furlan, Ioneide de Oliveira Campos e Kátia Vanessa Pinto de Meneses trabalharam na concepção, redação do texto e organização/análise de fontes. Hellayne Meneses Ribeiro e Lorrayne Marjory Menezes Rodrigues trabalharam na organização das fontes de dados.

\section{Notas}

${ }^{1}$ Parte da pesquisa Avaliação participativa do curso de Graduação em Terapia Ocupacional Faculdade de Ceilândia/UnB: metodologias ativas e o processo de ensino-aprendizagem para a formação profissional, coordenada pela Profa. Dra. Paula Giovana Furlan, com financiamento do Decanato de Ensino de Graduação/ Universidade de Brasília e aprovação no Comitê de Ética em Pesquisa em Seres Humanos FS/UnB 160/11. 